\title{
Nanotechnology in Detection of Food Toxins - Focus on the Dairy Products
}

\author{
Agnishwar Girigoswami ${ }^{1}$ (D), Mahashweta Mitra Ghosh ${ }^{2}$, Pragya Pallavi ${ }^{1}$, Seenuvasan Ramesh ${ }^{1}$, Koyeli \\ Girigoswami 1,* (D) \\ 1 Medical Bionanotechnology, Faculty of Allied Health Sciences, Chettinad Hospital and Research Institute, Chettinad \\ Academy of Research and Education, Chettinad Health City, Kelambakkam, 603103, Tamilnadu, India \\ 2 Department of Microbiology, St. Xavier's College, Kolkata, West Bengal \\ * Correspondence: koyelig@gmail.com;
}

Scopus Author ID 23060318900

Received: 20.01.2021; Revised: 23.02.2021; Accepted: 28.02.2021; Published: 7.03.2021

\begin{abstract}
Nanotechnology is the field of science which has been recently applied in different field of biomedical sciences, targeted drug delivery, imaging, theranostics, etc. The vast surface area to volume ratio of engineered nanostructures is utilized for designing many biosensors. Food production, processing, packaging, storage, and transport engage many kinds of chemicals and materials that may contribute some harmful effects on human health. These altogether are named as food toxins if their amount exceeds the safe limits for human consumption. We have searched the relevant articles in PubMed and Google scholar to write this review and selected the appropriate articles to prepare the manuscript. The detection of such food toxins can be done using conventional methods, but their sensitivity, time, and limit of detection and cost cost-effectiveness are a matter of concern. Nanotechnology has been used for designing different kinds of biosensors to overcome the barriers of low sensitivity. In this review, we will discuss nanotechnology's application in the detection of different kinds of food toxins, especially dairy products.
\end{abstract}

Keywords: food toxins detection; dairy products; biosensors; nanotechnology; food contaminants.

(C) 2021 by the authors. This article is an open-access article distributed under the terms and conditions of the Creative Commons Attribution (CC BY) license (https://creativecommons.org/licenses/by/4.0/).

\section{Introduction}

Nanotechnology involves the ability to reformulate metals and non-metals into new nanosized particles, with measurement under $100 \mathrm{~nm}$ in size and at the nanometer scale, the physical, chemical, and organic properties of different types of nanomaterials are generally unique compared to their bulk counterparts $[1,2]$. The difference is found due to the elevated surface area to volume ratio and quantum impacts. A huge surface area leads to progressively responsive compound properties and influences the mechanical or the electrical properties whereas, the quantum impacts influence the electrical, magnetic, and optical properties of the nanomaterials. Nanoparticles have been utilized in various fields like sanitization of material textures, water sterilization, biomedical imaging [1-4], theragnosis [5-6], nano-enabled drug delivery [7-8], food packaging, detection of food microorganisms and toxins, etc. Magnetic nanoparticles have been used for the immobilization of hydrolases to prevent their degradation. The different subclasses of the enzyme hydrolases are known to be immobilized on the magnetic nanoparticles with or without surface modification or are entrapped inside polymeric network support that contains magnetic nanoparticles. The applications of such immobilized hydrolases were elaborately reported earlier [9]. In another review article, the different types 
of glucose biosensors designed where GOx was immobilized on the electrode surface of the simple and surface modified single and multiwalled carbon nanotubes (CNTs) or the different kinds of derivatives of carbon nanostructures have been discussed [10]. Cantilever-based nano biosensors have also shown promising results in detecting pesticides in the soil, thereby showing the different applications of nano biosensors [11].

\section{Food Toxins}

Food toxins can be natural, chemicals, additives and pesticides, presence of metals.

\subsection{Natural toxins.}

These are the toxicants that are produced naturally by living organisms and do not cause any harm to the organisms themselves. Although these chemical compounds can be toxic to humans and other animals when consumed. These natural toxins have a range of chemical structures, have different biological functions, and are produced by the plants for their natural defense against microorganisms, predators, and insects or as a result of mold infestation or extreme climatic conditions. Other sources are known for the natural toxins like microscopic planktons and microorganisms present in oceans or lakes, producing chemical compounds that can be toxic for humans but may not be for the aquatic biota. The fish and shellfish which consume these organisms may not get affected, but when humans consume those shellfish, they can quickly get intoxicated. Some of the natural toxicants are Pyrrolizidine Alkaloids (PAs), poisonous mushrooms, solanines and chaconine (glycoalkaloids), Mycotoxins, goitrotgens, lectins, furocoumarins, cyanogenic glycosides (phytotoxins), aquatic biotoxins (algal toxins) etc.

\subsection{Chemicals.}

In food, many chemicals are incorporated intentionally or unintentionally during food processing, packaging, heating, and preparation. Industrial chemicals like dioxins, bisphenol A (BPA), etc., and chemicals related to heating like acrylamide are found in foods. Other chemicals like butylated hydroxytoluene (BHT), ethyl carbamate, perchlorate, furan, benzene, calcium propionate (microbial retardants), polychlorinated biphenyls (PCBs), etc. are incorporated into the food as an additive or a part of food processing and packaging. The different pesticides and herbicides used to prevent the crops are also retained by the grains and get incorporated into humans through their consumption. Food texturing agents, refining chemicals, flavor enhancers, antibiotics, and other drugs used in livestock are the further sources of harmful chemical incorporation through the food chain.

\subsection{Metals.}

Metals and metalloids are present in the air, water, as well as soil and a certain level is present in different types of foods depending on the growth condition of the crop, industrial manufacturing, and processing, processes used in agriculture, the DNA present in the food crops as well as the environmental conditions and geographic location of the food grown or harvested. Sometimes metals like iron or non-metals like iodine are also added externally in the foods such as breakfast cereals, infant formulas, salt, etc., as a nutritional supplement. However, there is a safe limit of metal concentrations in our body, and a metal overload may lead to toxic effects rather than any benefit. Iron poisoning can occur if we consume too much 
iron leading to severe vomiting, abdominal pain, diarrhea, dehydration followed by lethargy. Heavy metals like arsenic, mercury, and lead can cause severe illness and impairment if consumed at a high dose and can even lead to death [12].

\section{Detection of Food Pathogens and Toxins}

Several foodborne microorganisms are responsible for causing foodborne diseases due to the consumption of contaminated foods by different microorganisms like bacteria, viruses, and fungi. These foodborne pathogens cause food and water poisoning. Some of the wellknown bacteria are Salmonella enterica, Escherichia coli, Campylobacter Jejuni, Listeria monocytogens, Staphylococcus aureus, Bacillus cereus, and many more. Sometimes the pathogenic microorganisms themselves cause food poisoning, and sometimes the toxins released by them may pose health hazards to humans. The toxins produced by pathogenic microorganisms can target the eukaryotic cells by three mechanisms: (i) They can bind to the cell-specific receptors or general receptors present on the surface of the eukaryotic cells and exert their toxicity by cleaving the molecules exposed to the surface or generating pores in the membrane of the cell and break the permeability barrier. (ii) They can have some intracellular target, cross the cell membrane, and usually have two active domains. One of these domains they use to cross the cell membrane and the other for modifying the toxin's target. (iii) They have an intracellular target and get delivered directly by the bacteria [13].

Many methods are known for detecting pathogens and Gram-negative bacterial endotoxins or for the detection of endotoxin only. The only endotoxin detection method is capable of detecting the lipopolysaccharide (LPS) structure present on the Gram-negative bacterial outer membrane. The various kinds of detection methods for pathogens and endotoxins are discussed by Alahi \& Mukhopadhyay (2017) [14]. Listeria monocytogens are the food pathogen that can cause listeriosis characterized by encephalitis, meningitis, and septicemia, and its virulence factor is listeriolysin O (LLO). This LLO is produced by Listeria monocytogens and the LLO- encoding gene (hlyA) can be detected in the virulent strains where they are present. Blood agar and hemolysis assay can be easily employed to detect the protein toxin LLO and the different methods for its detection are discussed in a previous study mentioning the usefulness and drawbacks of these methods [15].

On the other hand, the food toxins from Gram-positive bacteria are detected using immunological, biological, molecular assays, and mass spectrometry. The most important toxins related to Gram-positive pathogens are the emetic toxins and diarrheal enterotoxins secreted from Bacillus cereus, enterotoxins released from Clostridium perfringens, neurotoxins from Clostridium botulinum, and an enterotoxins family produced from Staphylococcus aureus as well as some different staphylococci. All these toxins are the major virulence factors responsible for foodborne diseases, and the different detection methods are discussed by Rajkovic et al., 2020 [16]. Botulinum toxins detection using the mouse bioassay method has been discussed as we know that this toxin is used for cosmetic purposes. However, this method had limitations due to the small number of samples that can be analyzed at a time. The other methods of detection of this toxin are digoxigenin ELISA, biosensors, particularly multichannel immunosensors, electrochemiluminescence, Immunochromatographic assays, or lateral flow tests or simply strip HHAs were discussed in detail by other researchers [17]. The different kinds of lateral flow immunoassays (LFIA s) used to detect food toxins in agricultural foods have been extensively reviewed. The advancements in this assay regarding how the labels, the recognition elements, or the strategy for toxin detection were discussed. The LFIAs 
used to detect different bacterial toxins like Botulinum Toxin, Staphylococcal enterotoxin, Cholera toxin, Shiga toxin, Mycotoxins (Aflatoxins, Ochratoxin A, Fumonisins, Deoxynivalenol Zearalenone), and other miscellaneous toxins like Okadaic acid, Microcystins, Chlorpyrifos, Carbofuran and triazophos, Brevetoxins, Abrin-a has been discussed elaborately by Tripathi et al., 2017 [18]. The different immunoassay-based kits available for detection of toxins produced by Bacillus cereus and Staphylococcus aureus are discussed elaborately by Brett (2006) [19] with a detailed comparison between the efficiency of the different detection methods. There are some biochemical methods or conventional methods, antibody-based detection, as well as nucleic acid-based detection methods for the detection of various food toxins. The current applications, limitations of the known methods, and the future perspectives of the detection of pathogens and food toxins are reported earlier, mentioning the rapid detection methods [20-23]. An in silico approach has also been discussed using peptidomics, proteomics, and metabolomics along with food comic methods to describe the detection of foodborne pathogens like fungi and bacteria. They have also overviewed the applications of these techniques in biomarker discovery for pathogenicity of the foodborne pathogens, determined the mechanism of action, and studied the resistance of these pathogens upon inactivation in the food from animals and plants [24]. Some of the studies exploiting the methods for detecting food toxins are summarized below in Table 1.

Table 1. The different types of toxins produced by microorganisms and their detection methods.

\begin{tabular}{|c|c|c|c|c|}
\hline S No. & Assay used & $\begin{array}{l}\text { Nature of the Toxin } \\
\text { and } \\
\text { Organism }\end{array}$ & Finding of the study & Reference \\
\hline 1. & $\begin{array}{l}\text { HPLC conjugated } \\
\text { with the diode array } \\
\text { (DAD). } \\
\text { Fluorescence (FLD) } \\
\text { detectors were used } \\
\text { for toxin detection }\end{array}$ & $\begin{array}{l}\text { Aflatoxin B1,B2,G1,G2 } \\
\text { Producer organism: } \\
\text { Aspergillus flavus }\end{array}$ & $\begin{array}{l}\text { A new method has been developed for rapid, } \\
\text { sensitive, and simultaneous detection of Aflatoxin } \\
\text { B1, B2, G1, G2 quantities isolated from Fungus } \\
\text { Aspergillus flavus grown in laboratory culture } \\
\text { conditions. Here they have used HPLC, which is } \\
\text { equipped with a conventional diode array (DAD) } \\
\text { conjugated with a fluorescence detector (FLD). } \\
\text { Data was collected by growing the fungus in } \\
\text { different culture types, namely liquid slant culture, } \\
\text { submerged shake culture, and solid-state culture. } \\
\text { The conventional and improvised detectors both } \\
\text { detected the AFs with high sensitivity. This } \\
\text { method showed a recovery percent of } 76 \%-88 \% \\
\text { from the medium, spiked with different } \\
\text { concentrations ( } 2.5,10,50,100 \text {, and } 500 \mathrm{ng} / \mathrm{mL} \text { ) } \\
\text { of AFs. } \\
\text { In the case of FLD detector, the LOD (Limit OF } \\
\text { Detection) and LOQ (Limit of Quantification) for } \\
\text { assessing AFB1 and AFG1 were } 1.0 \mathrm{ng} / \mathrm{mL} \text { and } \\
2.5 \text { ng/mL, respectively, and the LOD and LOQ } \\
\text { for AFB2 and AFG2 were } 0.01 \text { and } 0.025 \mathrm{ng} / \mathrm{mL} \text {, } \\
\text { respectively. On the other hand, DAD could detect } \\
\text { as low as } 1.0 \mathrm{ng} / \mathrm{mL} \text { and quantify all the AFs as } \\
\text { low as } 2.5-5.0 \mathrm{ng} / \mathrm{mL} \text {. }\end{array}$ & [25] \\
\hline 2. & $\begin{array}{l}\text { Taq Man assay } \\
\text { along with an SYBR } \\
\text { green I real-time } \\
\text { PCR assay }\end{array}$ & $\begin{array}{l}\text { Emetic toxin cereulide. } \\
\text { Producer organism: } B . \\
\text { cereus }\end{array}$ & $\begin{array}{l}\text { Rapid, sensitive, and conclusive identification of } \\
\text { emetic B. cereus was made using TaqMan assay } \\
\text { along with an SYBR green I real-time PCR assay. } \\
\text { To eliminate false-negative results, the TaqMan } \\
\text { assay included an IAC. The SYBR green I-based } \\
\text { assay was found to be cost-effective for the } \\
\text { analysis of a large number of samples. This assay } \\
\text { has been being extended further to a duplex real- } \\
\text { time PCR which can perform one-step } \\
\text { differentiation of the emetic pathogens, B. cereus } \\
\text { and S. aureus. }\end{array}$ & [26] \\
\hline 3. & $\begin{array}{l}\text { Endopep-MS } \\
\text { method }\end{array}$ & $\begin{array}{l}\text { Botulinum Toxins A, B, } \\
\text { E, and F }\end{array}$ & $\begin{array}{l}\text { Here Endopep-MS method, a mass-spectrometric- } \\
\text { based endopeptidase method, has been used to }\end{array}$ & [27] \\
\hline
\end{tabular}




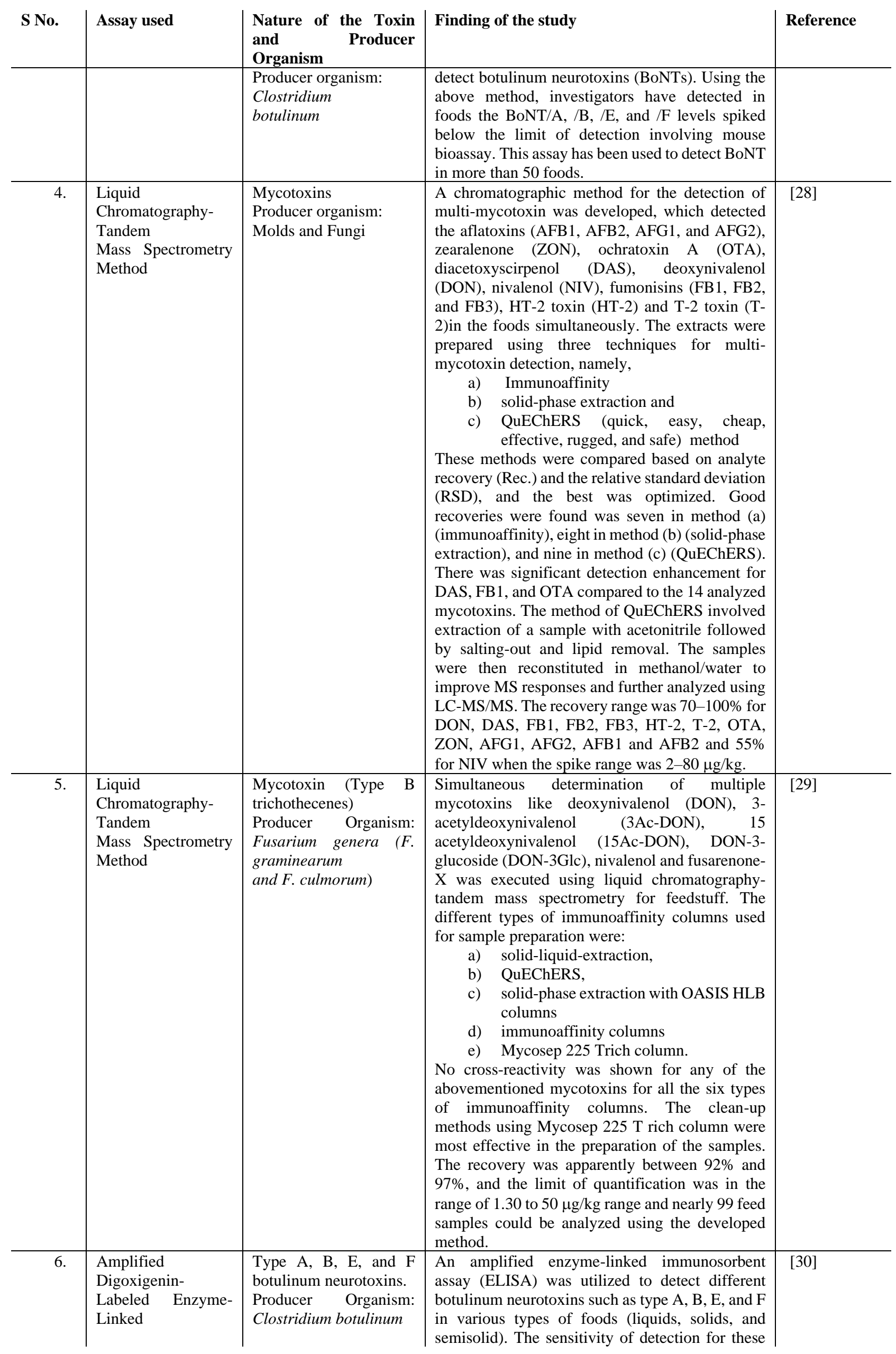




\begin{tabular}{l|l|l|l|l}
\hline S No. & Assay used & $\begin{array}{l}\text { Nature of the Toxin } \\
\text { and } \\
\text { Organism }\end{array}$ & Finding of the study & Reference \\
\hline & $\begin{array}{l}\text { ImmunosorbentAss } \\
\text { ay Antibodies }\end{array}$ & $\begin{array}{l}\text { botulinum complex serotypes was obtained to be } \\
60 \mathrm{pg} / \mathrm{ml}(1.9 \text { of } 50 \% \text { lethal dose [LD50]) for } \\
\text { botulinum neurotoxin type A (BoNT/A), 176 } \\
\text { pg/ml (1.58 LD50) for BoNT/B, 163 pg/ml for } \\
\text { BoNT/E (4.5 LD50), and } 117 \mathrm{pg} / \mathrm{ml} \text { for BoNT/F } \\
\text { (less than } 1 \mathrm{LD} \text { L5) in casein buffer. This assay was } \\
\text { very much effective in large-scale screening. }\end{array}$ &
\end{tabular}

There are many methods of detection of food toxins using nanotechnology, and several biosensors have been designed. Before discussing the applications of these biosensors in food toxin detection, we shall discuss in brief about biosensors.

\section{Biosensors}

A biosensor is a device that has a biological element that recognizes an analyte and then transduces the event to produce a signal which is proportional to the analyte concentration and conveys it to the detector. The recognition element should be highly specific and can combine with only the analyte of interest and not with any other interfering species. The analyte that can be detected can be an antigen, toxin, DNA, RNA, enzyme-substrate, protein, amino acid, microRNA, cell-specific antigen, and various disease biomarkers. The recognition element can be protein, enzyme, antibody, aptamer, microorganism, cell, ssDNA/RNA, etc. The types of transducers can be optical (absorbance/Fluorescence/Luminescence), calorimetric, change in $\mathrm{pH}$, electrochemical (Electrical conductivity, current or potential change), piezoelectric (mass change), acoustic, etc. The different types of sensing techniques used in biosensors are Fluorescence, DNA Microarray, SPR (Surface plasmon resonance), Impedance spectroscopy, SPM (Scanning probe microscopy, AFM, STM), QCM (Quartz crystal microbalance), SERS (Surface Enhanced Raman Spectroscopy), Electrochemical-Potentiometric, Amperometric, Conductimetric.

The detail about biosensors used in medical diagnosis is already discussed earlier [31-34]. A schematic diagram for biosensors is given in Figure 1.

The common types of biosensors used in detecting food toxins are electrochemical sensors, immunosensors, aptasensors, etc. Some of them are briefly discussed below:

\subsection{Electrochemical sensors.}

These particular analytical devices transduce energy obtained from biochemical reactions such as antigen-antibody reactions or enzyme-substrate reactions to electrical signals. The electrical signals include current, voltage, impedance, frequency, etc. An electrode is a key component in electrochemical biosensors that provides solid support for biomolecules' immobilization like an antibody, enzyme, and nucleic acids. The journey of electrochemical biosensors started with the development of the $1^{\text {st }}$ version of the blood glucose sensor. Presently an ample number of electrochemical biosensors are introduced and commercialized for diverse applications.

A common electrochemical biosensor consists of a bioreceptor that can bind to a specific target to generate the signal in the form of an electron that will be measured electronically using a transducer and data analysis devices [35]. The biorecognition element can be antibodies, enzymes, nucleic acids, aptamers, proteins, etc. The addition of nanomaterials as a part of biosensors has given a new direction towards better sensitivity due 
to their high surface-to-volume ratio. The capacity of loading biomolecules or the immobilization of biorecognition elements has also improved due to the same reason.

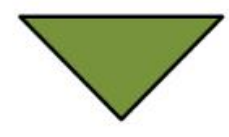

Analyte of interest

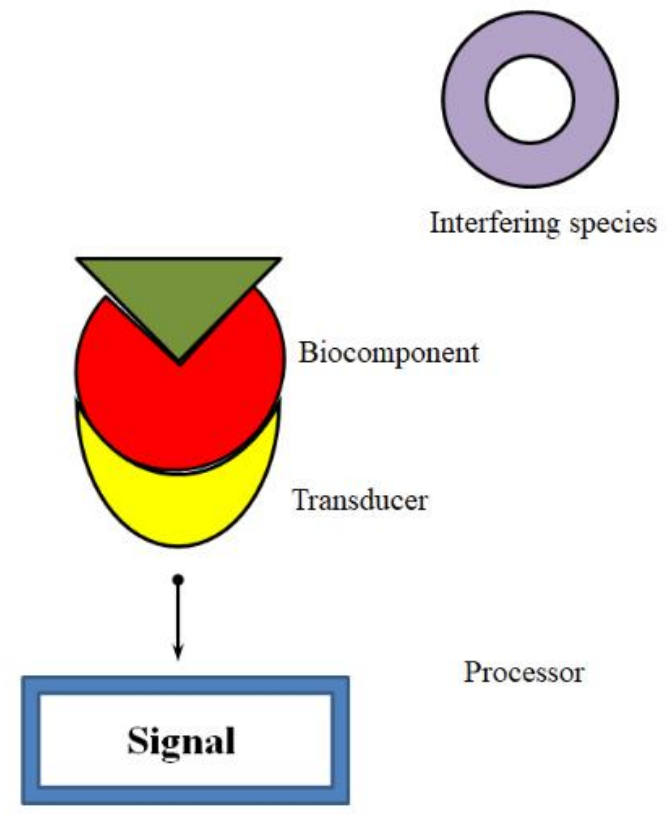

Figure 1. A schematic representation of biosensors. The analyte of interest is recognized by the biocomponent or recognition element, and the binding event is converted to a detectable signal by the transducer. The processor reads this signal.

Another important factor in the electrochemical biosensors is the transducer. The transducer is a combination of electrodes and electrolytes [36, 37]. The sensitivity depends on the specific materials used to design the transducers, and the signal translation rate is related to the properties of the surface. In this regard, gold electrodes, carbon-based electrodes, conducting polymers, metal oxides, and nanocomposites are well known [38-41].

The electrochemical biosensors' operating principle depends on the specific transducers that convert biochemical signals to the detectable electronic response. It can be potentiometric or amperometric, or impedimetric. Potentiometric transducers generally work on the ionselective principle, and they are widely used to detect several bioanalytes like glucose, triglycerides, pesticides, etc. [42]. Potentiometric transducers generally have poor sensitivities. Typically noble metals are used to design the working electrodes of the amperometric transducers [43]. The current produced at the working electrode is measured concerning a reference electrode after application of certain potential. The current produced is directly proportional to the degree of oxidation or reduction of the analytes to be identified. These types of biosensors are comparatively simple and cost-effective. The impedimetric biosensors are label-free and highly sensitive biosensors. In impedimetric biosensors, the receptor-analyte interaction is related to the impedance change. The working electrode's surface plays a crucial role in this type of electrochemical biosensor [44]. The change in impedance is monitored to analyze the frequency change concerning the time. It should be noted that the impedance is related to two major factors - resistance and capacitance. This type of electrochemical biosensors' major drawbacks are slow response time and complicated models to calculate the response. The electrochemical biosensors can be employed to detect toxins like food additives present in foods. Several synthetic dyes like metanil yellow etc., are illegally added into the food items to generate bright colors to attract food consumers. These synthetic dyes are banned by the food regulatory bodies even though these are available and regularly added in sauces, 
soft drinks, spices, juices, etc. These banned synthetic dyes are a great threat to human health, and most of them are potent mutagen [45]. WHO has already classified these dyes like metanil yellow as category II toxin that promotes cancer and can damage the gastric mucin. Some classified food additives like fast green were also established as neurotransmitter blockers. Therefore, it is necessary to quantify the food additives for the benefit of public health and quality control assurance. In addition to synthetic dyes, foodborne contaminants are also present, including microbial pathogens and their toxins. Electrochemical biosensors and nanosensors were developed worldwide to assess the various targets causing health hazards like pesticides, neurochemicals, mycotoxins, pathogens, etc. [37, 46, 47].

The change in voltammetric behavior of metanil yellow present in curcumin was assessed recently on glassy carbon electrodes, and carbon dots modified glassy carbon electrodes [48]. Gupta et al. have reported the importance of reliable, sophisticated, sensitive, and cost-effective electrochemical biosensors for food toxin detection [44]. Nanomaterialsbased electrochemical biosensors were employed for the detection of mycotoxins. Metanil yellow and fast green were also detected recently on glassy carbon electrodes coated with calixarene and gold nanoparticles. The sensitivity was established using electrochemical impedance spectroscopy, cyclic voltammetry, and differential pulse voltammetry [49].

\subsection{Immuno-chemical biosensors.}

Immunoassays are -established bio-analytical and clinical methods used in the laboratory regularly to quantify the analytes using the reactions between an antigen and an antibody. The immunochemical assays include Enzyme-linked immunosorbent assay (ELISA), radioimmunoassay, immunoaffinity column assay, and immunosensors. Radioimmunoassay is the simplest immunoassay technique that was initially developed for the biorecognition of insulin molecules.

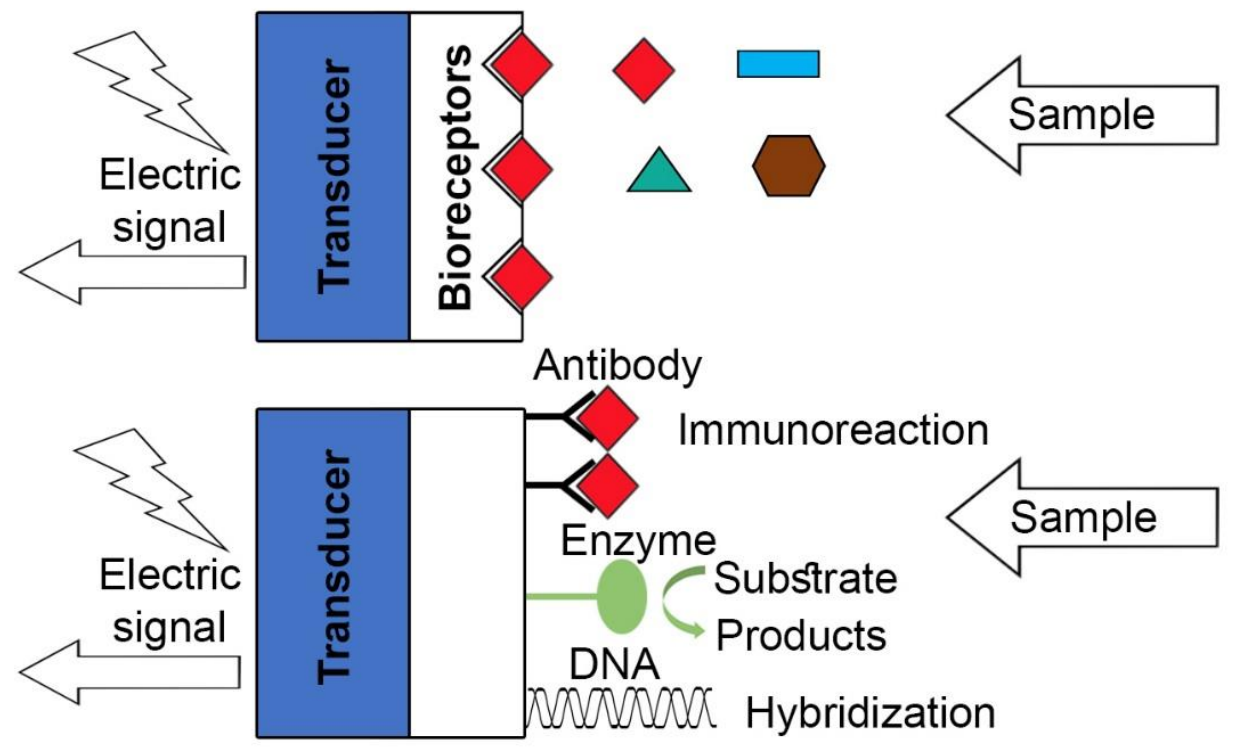

Figure 2. The schematic diagram showing (a) the specificity of a bioreceptor (b) the interaction between antigen-antibody, enzyme-substrate, DNA hybridization, which is to be detected by the biosensor.

The immunosensing phenomenon has numerous applications, including the development of a new class of biosensors. Therefore, a sensor that detects analytes or antigens of interest with the concept of immunoassay utilizing specific antibodies to generate stable immunocomplex is termed as an immunosensor. The amount of stable immunocomplex is 
measured by combining this reaction to the surface of specialized transducers. After the detection of immunocomplex, the transducer converts it to the electrical signal to be processed. The ideal immunosensors should have the ability to identify the target antigens fast and generate stable immunocomplex without supplementary reagents. The high reproducibility and ability to detect the target analytes in real samples are also required for the ideal immunochemical biosensors [50]. The affinity-based biosensors like immunosensors, DNAbased biosensors, etc., are shown in Figure 2.

\subsection{Aptamer-based biosensors.}

Aptamers are known to be single-stranded nucleic acids that can specifically bind to the target molecules to generate a secondary structure. The binding of aptamers with their specific molecules generates distinct conformations such as G-quadruplex and hairpin. The conformational variations before and after binding specific biomolecules offer a great opportunity and feasibility for designing aptamer-based biosensors. The aptamers for the specific biomolecules are generated using Sequential Evaluation of Ligands by Exponential Enrichment (SELEX) methods, a combinatorial biology technique [51]. Aptamers can replace the antibodies in ELISA due to their behavior, like affinity ligands. Aptamers are well established for their adaptive binding to bring a large conformational change. These conformational changes alter the local environment and are crucial to avoid non-specific interaction, which is very important to design the biosensors. Aptamers are promising in the present day due to their certain advantages over antibodies. Aptamers can be synthesized via chemical progress that is more cost-effective than the production of antibodies. Since Aptamers are nucleic acids, they can more easily be modified using simple chemistry for signal improvements and the attachment of electrochemical probes, optical probes, or quenchers. These advantages have made them an ideal candidate for the fabrication of biosensors. Aptamers can interact with DNA or RNA molecules like DNAzymes to fabricate a new class of oligonucleotide instruments for biosensing applications.

\section{Nanotechnology-Based Detection of Food Toxins}

Various systems have been developed to tackle food safety-related issues to recognize biological and chemical contaminants in food. Among these methodologies, nanomaterialdependent biosensors contribute a rapid, sensitive, proficient, and compact detection, defeating the limitations and restrictions of conventional techniques, for example, rigorous pre-treatment of samples, long recognition time, and depending on costly instruments and skilled personnel to execute the experiment. In a previous study, an extensive review has been done for the class of food contaminants, including pathogens/toxins, metals, pesticides, veterinary medications, and non-permissible additives. In every food contaminant classification, the nanobiosensing procedures are summarized, including optical, colorimetric, fluorescent, electrochemical, and safe biosensors; the important analytes nanomaterials biosensors are explained elaborately along with future limitations [52]. We have seen in the previous section that the food pathogens and toxins produced by different food pathogens can be detected using various analytical methods. In the following table 2 we have summarized nanotechnology's use in the detection of food pathogens and toxins. 
Table 2. The different nanomaterials and nanobiosensors used for the detection of pathogens present in food and food toxins.

\begin{tabular}{l|l} 
S No. & Nanomaterial used/ discussed \\
\hline 1. & $\begin{array}{l}\text { Carbon nanomaterials- Carbon } \\
\text { Nanotubes, Fullerenes, } \\
\text { Graphene and its derivatives like } \\
\text { Reduced Graphene Oxide, } \\
\text { Graphene Oxide. }\end{array}$
\end{tabular}

\begin{tabular}{l|l}
\hline 2. & $\begin{array}{l}\text { Noble metal-based } \\
\text { nanomaterials- gold, silver and } \\
\text { bimetallic nanomaterials }\end{array}$
\end{tabular}

(2)

3. $\quad$ Electrochemical biosensors, aptasensors, immunosensors, Molecular imprinted polymer (MIP), optical biosensors etc. for the detection of mycotoxins

\begin{tabular}{l|l|}
\hline 4. & $\begin{array}{l}\text { Biosensors for detection of food } \\
\text { toxins }\end{array}$
\end{tabular}

2.

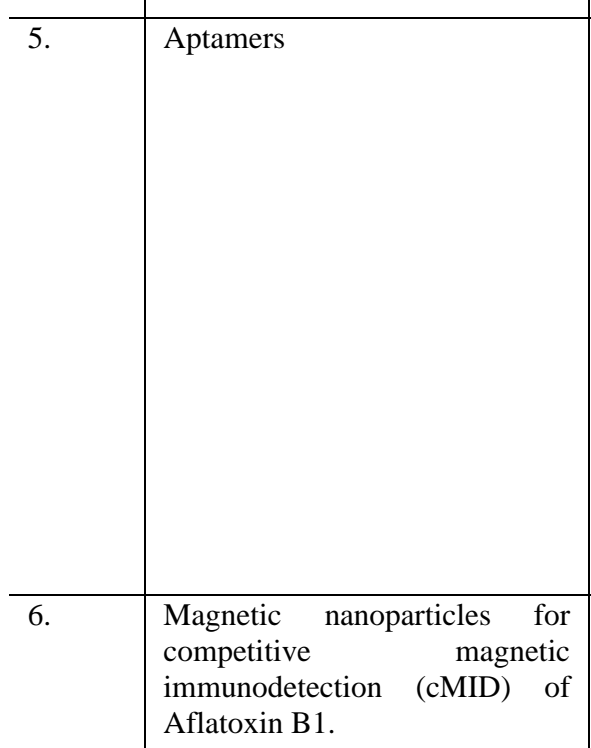

Finding of the study

The review paper discussed the different carbon-based nanomaterials elaborately and the different food toxins like Plant Toxins, Bacterial Pathogens, Mycotoxins and Aflatoxin. They mainly focussed on the detection of different types of Aflatoxins using carbon nanostructure-based biosensors. The carbon nanotubes are profoundly used in designing electrochemical sensors for Aflatoxin detection by growing the CNTs directly on the surface of the electrodes or adsorption of CNTs on the existing electrodes, or embedding the CNTs on the polymer coatings or to use them in binders for designing paste electrodes. The electrochemical properties of reduced Graphene oxide were also used to design biosensors for the detection of Aflatoxins.

The second review (2015) discusses the carbon nanomaterials used for the detection of mycotoxins.

This review discussed the different types of noble metal nanomaterial-centered aptasensors and their development to detect a microbial toxin. The metal nanomaterials discussed in this review are gold nanoparticles, gold nanoclusters, gold nanorods, silver nanoclusters, silver nanoparticles, and bimetallic nanomaterials. The different types of Aptasensors based on these metal nanomaterials showed high selectivity as well as sensitivity and can become a promising tool for the detection of pathogenic toxins. This book chapter discussed the different purification methods of mycotoxins using Supercritical fluid extraction (SFE), Liquid-liquid extraction (LLE), and solid-phase extraction (SPE), as well as nanobiosensors for the detection of mycotoxins. The other types of detection like mimotope and detection using inhibition of enzymes like acetylcholinesterase (AChE) was also described.

This monograph summarises the enzymatic biosensors, antibody-based biosensors, ion channel switch- and lipid film-based biosensors, oligonucleotide and nucleic acid-based biosensors, and tissue, microorganisms, organelles, and cell-based biosensors for the fast detection of food toxins.

The review paper discusses the different DNA aptamers utilized for the detection of food toxins and heavy metals. It elaborately explains the use of different kinds of aptamer-based biosensors like fluorophore-modified aptamer sensors, including single fluorophore aptamer probes and (II) bischromophoric probes, FRET aptamer probes used in molecular beacon showing conformational change for the output signal, and FRET structure-switching probes for aptamers. Different types of DNAzymesaptamer interactions for the detection of mycotoxins are also discussed. The quenching of aptamers using graphene oxide (GO) was shown as it is known that GO demonstrates intrinsic characteristics of energy/electron transfer over a broad range of wavelength.

In this study, a highly sensitive assay technique for aflatoxin $\mathrm{B} 1$ is described using competitive magnetic immunodetection (cMID), and a competitive ELISA was optimized as a reference method by checkerboard titration. The immunofiltration columns used for this cMID process were layered with aflatoxin B1-BSA conjugate and used for the purpose of competitive enrichment of the biotinylated aflatoxin B1- specific antibodies. Furthermore, the magnetic nanoparticles were functionalized with streptavidin and were
Reference

$[53,54]$

[51]

[55] 


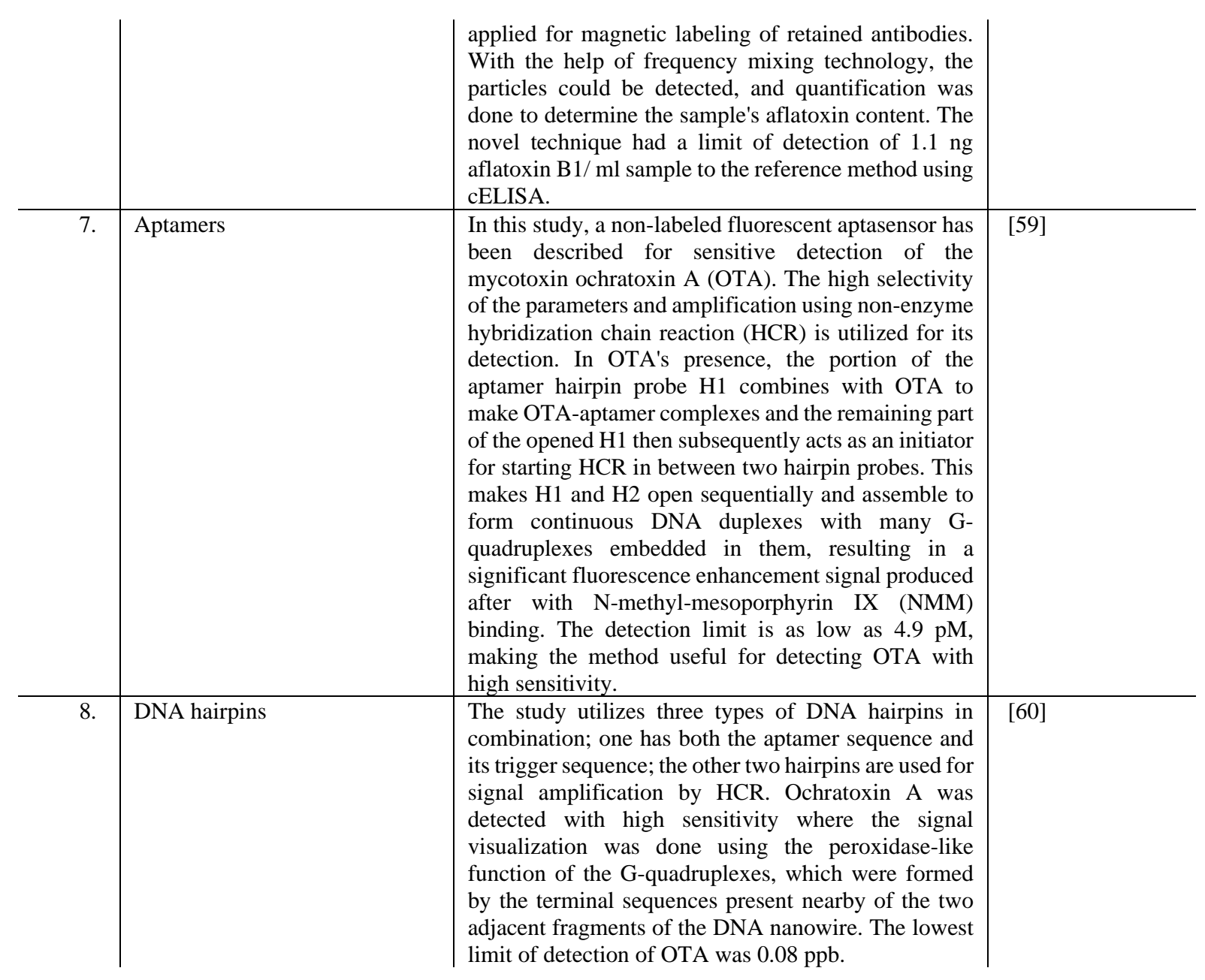

\section{Toxins in Dairy Products}

Milk is viewed as the ideal food because of its neonates, children, and adults' requirements and is probably the best source of protein, fat, sugar, nutrient, and minerals. Tragically, milk and milk products are mostly adulterated worldwide to fulfill the demand and supply gap, the low purchasing capacity of the client, the perishable nature of milk, and the absence of reasonable detection tests [61]. The toxins involved in the dairy products include bisphenol A, melamine, aflatoxin, Bacillus cereusis, etc.

\subsection{Aflatoxin.}

Aflatoxins are generated by three types of Aspergillus species - A.flavus, A. parasiticus, and A. nomius. Aflatoxin B1 (AFB1) is the most common product of the Aspergillus species and is harmful for lactating animals, for example, cows, humans, and goats, if they consume foodstuffs contaminated with AFB1. AFB1 can pass on to the milk in the form of aflatoxin M1 (AFM1) at 0.3-6.3\% level. AFM1, the monohydroxylated derivative of AFB1, is similarly harmful to AFB1, but the cancer-causing and mutagenic potential are lower. AFM1 can be seen in various food products such as dried milk, milk, yogurt, butter, cheese, and infant formula. It is known that milk and milk products are significant sources of nutrients for humans; the AFM1contamination is likely to harm human health [62]. 


\subsection{Melamine.}

Melamine (2,4,6-triamino-1,3,5-triazine, MA), has a chemical formula as C3H6N6 and has a wide application in industry for the production of plastic silverware and fire retardants, MA-formaldehyde polymer resins for producing covers, coatings, glues, and plastics. The high nitrogen content ( $66.6 \%$ by mass) of MA was used to adulterate the dairy products to elevate the clear protein content falsely. A delicate, simple, and quick detection of small MA amounts in milk products were accomplished using a reusable, convenient optical sensor dependent on the guideline of immunoassay and evanescent wave-excited fluorescence. This upgraded immunosensor used MA-BSA conjugates on the test surface and detected MA using EWFI platform yielding higher affectability, better specificity, and simple to-utilize accessibility for quick identification of MA contamination in dairy products. They have also shown simultaneous detection of many other contaminants using the proposed EWFI system utilizing the quantum dots of various sizes to capture various antibodies that can bind with various contaminants [63].

\subsection{Bisphenol A.}

Bisphenol A (BPA) is an organic material commonly used to synthesize epoxy resins, polyvinyl chloride, and polycarbonate plastics. In the packaging of milk and milk products, plastics are used, and during the storage of these dairy products, BPA gets leached into the food. This leaching may cause the food to have more than the permissible amount, which can pose a health hazard because it is an endocrine disruptor. It has pseudoestrogenic properties due to the presence of phenolic structure; thus, it can interact with the estrogen receptors and play a role as an agonist or antagonist through the estrogen receptor (ER) mediated pathways signaling. This enables BPA to contribute significantly in different diseased conditions like infertility in female and male, the formation of tumors which are hormone-dependent like breast and prostate cancer, precocious puberty, and a variety of metabolic disorders such as polycystic ovary syndrome (PCOS). BPA gets metabolized by the liver to produce bisphenol A glucuronide, and most of this compound is eliminated through the urine. Everyday exposure and the bioaccumulation in our body warrants its biomonitoring [64]. Thus, this is a major toxin that needs to be monitored for its dairy products.

\subsection{Bacillus cereus.}

Bacillus cereus is a universal, spore-forming microscopic organism that can tolerate pasteurization and most of the dairy industry's sterilization procedures. Being a pathogen, it is shown to be responsible for various sorts of food contamination, and one kind of foodborne disease brought about by B. cereus is the diarrheal disorder, which is caused due to vegetative cells ingestion that produces toxins in our digestive system. The toxins responsible for the diarrheal condition are hemolysin BL (HBL), cytotoxin $\mathrm{K}$ (CytK), and nonhemolytic enterotoxin (NHE). Furthermore, enterotoxin T (BceT), FM (EntFM), and hemolysin II (Hly II) were additionally depicted as possible diarrheal toxins, even though there is a lack of evidence that can demonstrate that they can cause food contamination. HBL is a three-segment toxin that comprises two lytic proteins, L1 and L2, which are encoded by $h b l D$ and $h b l C$ genes, respectively, and a binding segment $\mathrm{B}$ encoded by $h b l A$ gene. For the exertion of effective toxicity, the presence of each of the three segments together is essential [65]. 


\section{Nanotechnology-Based Toxin Detection in Dairy Products}

Many reports have exploited the use of biosensors for food contaminants detection, and the most common nanomaterials used for the detection are (i) Gold nanoparticles (GNPs), silver nanoparticles (AgNPs) because they possess surface platform resonance (SPR) characteristics and have high conductivity which is required in optical as well as electrochemical sensors, (ii) magnetic NPs, e.g., $\mathrm{Fe}_{2} \mathrm{O}_{3} \mathrm{NPs}$ which can provide magnetic functions that can be utilized for the separation of the analytes efficiently (iii) carbon nanotubes (CNTs) and all the graphene-based nanomaterials which can amplify the electrochemical signals because of their high electrical conductivity [66].

Gold nanoparticles possess extraordinary optical properties at their nanoscale, being wine red in color of gold nanoparticles (GNPs) which become blue in color when they aggregate. This property has been exploited to design many biosensors for dairy toxins detection. Radoi et al. established five various clones of antibodies against the aflatoxin M1 and employed the classical indirect and direct competitive Enzyme-Linked Immunosorbent Assay (ELISA) assays which the direct competitive ELISA utilized the superparamagnetic nanoparticles. The investigation aimed to improve the detection time of classical ELISA techniques by decreasing the coating, blocking, and competition step. The study demonstrated that a total dc-ELISA (coating, blocking, and the step of competition) using superparamagnetic nanoparticles reduced the detection time to $40 \mathrm{~min}$, including a $20 \mathrm{~min}$ coating step. The detection limit of AFM1 in milk had a broad working range between 4-250 ng/L with an IC50 value of $15 \mathrm{ng} / \mathrm{L}$. The matrix impact and the rate of recovery showed nearly $100 \%$ recovery [67]. A rapid aflatoxin M1 (AFM) detection method exhibiting high sensitivity was designed based on dynamic light scattering using a gold nanoprobe that was coupled with superparamagnetic beads. These nanoprobes were made by conjugation of bovine serum albumin (BSA) and AFM (AFM-BSA), BSA, and GNPs. The magnetic beads-based immunosorbent assay (MBISA) was capable of measuring the AFM concentration by directly competing with the nanoprobes, and the concentration of the nanoprobes was detected using DLS. There was a positive proportionality observed between the AFM concentration and DLS results. Moreover, the TEM imaging confirmed the as-prepared nanoprobes' attachment with the magnetic beads via antigen-antibody reaction. In comparison with conventional ELISA, MBISA reduced the time of incubation significantly to $15 \mathrm{~min}$, and there was no time required for the development of color, thereby simplifying the process of AFM detection. The detection limit for AFM was $37.7 \mathrm{ngL}^{-1}$ in buffer solution and 3-27.5 $\mathrm{ngL}^{-1}$ for AFM present in milk [68]. A recent review paper has explored the other methods of nanotechnology using nanomaterials such as Au/Ag nanoparticles (Au/Ag NPs), magnetic nanoparticles (MNPs), carbon-based nanoparticles (CBNs), Quantum dots (QDs) as well as novel nanomaterials, which includes upconversion nanoparticles (UCNPs), nanomaterial-functional DNA intelligent hydrogels and metal-organic frameworks (MOFs) and other hybrid nanostructures for the detection of aflatoxin [69].

Wei et al. described a procedure for fast and easy identification of melamine in food and different substances using unmodified gold nanoparticles, which can give an enhanced colorimetric signal when they precipitate with the chemical-specific for melamine. Cyanuric acid, which can form precipitates when interacting with melamine through highly specific hydrogen bonds, was used to detect melamine in milk. In this study, the signal outcome from the change in color due to specific precipitation with gold nanoparticles and cyanuric acid was 
combined, resulting in accurate melamine detection. The melamine specificity was confirmed by adding another amine, ATP, to see the effect of interfering species, and the results showed that the GNPs were specific for melamine only, and the sensitivity of detection was nearly 40 ppb [70]. In another study, melamine was detected in milk using 3-mercapto-1propanesulfonate-changed gold nanoparticles (MPS-GNPs) probe using a colorimetric assay. Since melamine has many $-\mathrm{NH}_{2}$ groups, the MPS could interact with these amine groups and, through strong hydrogen bonding, can precipitate the MPS-GNPs resulting in a color change from wine red to blue. The detection of this color change was recorded using a spectrophotometer. A further modification was made by introducing $\mathrm{NaCl}$ to the GNPs solution, which enhanced detection limits. The absorbance ratio at $650 \mathrm{~nm}$ to $520 \mathrm{~nm}$ was linear in a range of melamine concentration, and the lower limit of detection was $8 \mathrm{ng}$ which was far less than the safe limit of consumption of melamine [71].

BPA was detected using poly(amidoamine) (PAMAM) and $\mathrm{Fe}_{3} \mathrm{O}_{4}$ magnetic nanoparticles improvised glassy carbon electrode (GCE) using an electrochemical biosensor. The modified electrode significantly increased the oxidation peak current of BPA and reduced the oxidation overpotential, thereby improving the BPA detection level. There was a linear increase in oxidation current with the increase in BPA concentration in the range between $1 \times 10^{-8}-3.07 \times 10^{-6} \mathrm{M}$ having a correlation coefficient of 0.9996 , showing a limit of detection $5 \times 10^{-9} \mathrm{M}$. The steady-state current reached $95 \%$ within $6 \mathrm{~s}$, and a biosensor with improved sensitivity was obtained [72]. A SERS method using GNPs along with $\mathrm{Zn}^{+2}$ as an aggregation agent was used to detect BPA. The BPA detection limit was $4.3 \times 10^{-9} \mathrm{~mol} / \mathrm{L}$ (equal to $0.98 \times$ $10^{-3} \mathrm{mg} / \mathrm{kg}$ and the assay had a good linear relationship $\left(\mathrm{R}^{2}=0.990\right)$ calculated between the SERS signal intensity and the logarithm of the concentration of BPA in the range of $1.0 \times 10^{-}$ ${ }^{8}-1.0 \times 10^{-3} \mathrm{~mol} / \mathrm{L}$. A sensitive BPA detection method in milk was thus established [73].

Aptamer sequence was designed to bind with $\mathrm{B}$. anthracis and B. cereus spores, and an impedimetric aptasensor was designed for its detection. The molecular beacons designed by these aptamers detected the spores of $B$. cereus and B. thuringiensis with enhanced fluorescence intensity but did not detect the vegetative cells. The B.cereus spores were detected in a linear range of $10^{4} \mathrm{CFU} / \mathrm{ml}$ to $5 \times 10^{6} \mathrm{CFU} / \mathrm{ml}[74,75]$. B. cereus vegetative cells were also detected in another study using phage endolysin modified SPR chips utilizing subtractive inhibition assay. The limit of detection was $10^{2} \mathrm{CFU} / \mathrm{ml}$ [76]. A detailed application of nanotechnology in detecting food additives and toxins is reviewed by Vidic et al., 2020 [77].

\section{Conclusion}

Advances in nanotechnology have exhibited its appropriateness in the territories of food production, packaging, processing, and safety. The different types of food toxins and their detection using conventional methods and nanotechnology investigated so far have been discussed. It has been found that there are various kinds of biosensors, like immunosensors, electrochemical sensors, aptamer-based electrochemical sensors etc., that are being used to facilitate food toxin detection. The different food toxins and microorganisms present in dairy products are also described in the above review. The leaching of bisphenol A from the packaging of the dairy products; aflatoxins, the kind of mycotoxins that pose health hazards; melamine with high nitrogen content, and adulteration of milk and some microorganisms whose spores do not get killed even after pasteurization of milk, were discussed. The application of nanotechnology in detecting these additives in dairy products gives us an insight into the rapid and sensitive methods. Even though nanotechnology in foods has advanced a 
long time, further study is essential to augment the number of uses inside the food industry. Moreover, it is vital to standardize test methods to estimate the effect of these engineered nanomaterials.

\section{Funding}

This research received no external funding.

\section{Acknowledgments}

The authors are grateful to the Chettinad Academy of Research and Education for providing the infrastructural support.

\section{Conflicts of Interest}

The authors declare no conflict of interest.

\section{References}

1. Haribabu, V.; Sharmiladevi, P.; Akhtar, N.; Farook, A.S.; Girigoswami, K.; Girigoswami, A. Label free ultrasmall fluoromagnetic ferrite-clusters for targeted cancer imaging and drug delivery. Current Drug Delivery 2019, 16, 233-241, https://doi.org/10.2174/1567201816666181119112410.

2. Sharmiladevi, P.; Akhtar, N.; Haribabu, V.; Girigoswami, K.; Chattopadhyay, S.; Girigoswami, A. Excitation Wavelength Independent Carbon Decorated Ferrite Nanodots for Multimodal Diagnosis and Stimuli Responsive Therapy. ACS Appl Bio Mater 2019, 2, 1634-1642, https://doi.org/10.1021/acsabm.9b00039.

3. Haribabu, V.; Girigoswami, K.; Sharmiladevi, P.; Girigoswami, A. Water-nanomaterials interaction to escalate twin-mode magnetic resonance imaging. ACS Biomaterials Sci Eng 2020, 6, 4377-4389, https://doi.org/10.1021/acsbiomaterials.0c00409.

4. Sharmiladevi, P.; Haribabu, V.; Girigoswami, K.; Abubacker, S.F.; Girigoswami, A. Effect of Mesoporous Nano Water Reservoir on MR Relaxivity. Scientific Rep 2017, 7, https://doi.org/10.1038/s41598-017-117102 .

5. Haribabu, V.; Girigoswami, K.; Girigoswami, A. Magneto-silver core-shell nanohybrids for theragnosis. Nano-Struc Nano-Objects 2021, 25, https://doi.org/10.1016/j.nanoso.2020.100636.

6. Girigoswami, A.; Wafic, Y.; Sharmiladevi, P.; Haribabu, V.; Girigoswami, K. Camouflaged nanosilver with excitation wavelength dependent high quantum yield for targeted theranostic. Scientific Rep 2018, 8, https://doi.org/10.1038/s41598-018-34843-4.

7. Ghosh, S.; Girigoswami, K.; Girigoswami, A. Membrane encapsulated camouflaged nanomedicines in drug delivery. Nanomedicine 2019, 14, 2067-2082, https://doi.org/10.2217/nnm-2019-0155.

8. Amsaveni, G.; Farook, A. S.; Haribabu, V.; Murugesan, R.; Girigoswami, A. Engineered multifunctional nanoparticles for DLA cancer cells targeting, sorting, MR imaging and drug delivery. Adv Sci Eng Med 2013, 5, 1340-1348, https://doi.org/10.1166/asem.2013.1425.

9. Husain, Q. Magnetic nanoparticles as a tool for the immobilization/stabilization of hydrolases and their applications: An overview. Biointerface Res Appl Chem 2016, 6, 1585-1606.

10. Husain, Q. Carbon nanotubes mediated immobilized glucose oxidase biosensors as an effective and sensitive analytical tool. Biointerface Res Appl Chem 2018, 8, 3060-3074.

11. Muenchen, D.K.; Martinazzo, J.; de Cezaro, A.M.; Rigo, A.A.; Brezolin, A.N.; Manzoli, A.; de Lima Leite, F.; Steffens, S.; Steffens, J. Pesticide Detection in Soil Using Biosensors and Nanobiosensors. Biointerface Res Appl Chem 2016, 6, 1659-1675.

12. Stadler, R.H.; Lineback, D.R. Process-Induced Food Toxicants: Occurrence, Formation, Mitigation, and Health Risks. $1^{\text {st }}$ ed.; John Wiley \& Sons Inc., 2008; https://doi.org/10.1002/9780470430101.

13. Blanke, S.R. Portals and pathways: Principles of bacterial toxin entry into host cells. Microbe 2006, 1, 2632.

14. Alahi, M.E.E.; Mukhopadhyay, S.C. Detection Methodologies for Pathogen and Toxins: A Review. Sensors (Basel) 2017, 17, https://doi.org/10.3390/s17081885.

15. Churchill, R.L.; Lee, H.; Hall, J.C. Detection of Listeria monocytogenes and the toxin listeriolysin O in food. J Microbiol Methods 2006, 64, 141-70, https://doi.org/10.1016/j.mimet.2005.10.007.

16. Rajkovic, A.; Jovanovic, J.; Monteiro, S.; Decleer, M.; Andjelkovic, M.; Foubert, A.; Beloglazova, N.; Tsilla, V.; Sas, B.; Madder, A.; De Saeger, S.; Uyttendaele, M. Detection of toxins involved in foodborne 
diseases caused by Gram-positive bacteria. Comprehensive Reviews in Food Science and Food Safety 2020, 19, 1605-1657, https://doi.org/10.1111/1541-4337.12571.

17. Sharma, S.K.; Whiting, R.C. Methods for detection of Clostridium botulinum toxin in foods. J Food Prot 2005, 68,1256-1263, https://doi.org/10.4315/0362-028x-68.6.1256.

18. Tripathi, P.; Upadhyay, N.; Nara, S. Recent advancements in lateral flow immunoassays: A journey for toxin detection in food. Critical Rev Food Sci Nutrition 2018, 58, 1715-1734, https://doi.org/10.1080/10408398.2016.1276048.

19. Brett, M.M. Kits for Detection of Food Poisoning Toxins Produced by Bacillus cereus and Staphylococcus aureus. In: Foodborne Pathogens. Adley, C.C. (eds) Methods Biotech Humana Press. 2006; pp. 21, https://doi.org/10.1385/1-59259-990-7:091.

20. Ge, B.; Meng, J. Advanced Technologies for Pathogen and Toxin Detection in Foods: Current Applications and Future Directions. JALA: Journal of the Association for Laboratory Automation 2009, 14, 235-241, https://doi.org/10.1016/j.jala.2008.12.012.

21. Mandal, P.K.; Biswas, A.K.; Choi, K.; Pal, U.K. Methods for rapid detection of foodborne pathogens: an overview. American J Food Tech 2011, 6, 87-102, https://dx.doi.org/10.3923/ajft.2011.87.102.

22. Pimbley, D.W.; Patel, P.D. A review of analytical methods for the detection of bacterial toxins. $J$ Appl Microbiol Symposium Supplement 1998, 84, 98S-109S, https://doi.org/10.1046/j.13652672.1998.0840s198S.x.

23. Zhao, X.; Lin, C.-W.;Wang, J.; Oh, D.H. Advances in Rapid Detection Methods for Foodborne Pathogens. J Microbiol Biotechnol 2014, 24, 297-312, http://dx.doi.org/10.4014/jmb.1310.10013.

24. Martinović, T.; Andjelković, U.; Gajdošik, M.Š.; Rešetar, D.; Josić, D. Foodborne pathogens and their toxins. J Proteomics 2016, 147, 226-235, https://doi.org/10.1016/j.jprot.2016.04.029.

25. Alshannaq, A.F.; Yu, J.-H.A Liquid Chromatographic Method for Rapid and Sensitive Analysis of Aflatoxins in Laboratory Fungal Cultures. Toxins 2020, 12, https://doi.org/10.3390/toxins12020093.

26. Fricker, M.; Messelhäußer, U.; Busch, U.; Scherer, S.; Ehling-Schulz, M. Diagnostic real-time PCR assays for the detection of emetic Bacillus cereus strains in foods and recent food-borne outbreaks. Appl Environ Microbiol 2007, 73, 1892-1898, https://doi.org/10.1128/AEM.02219-06.

27. Kalb, S.R.; Krilich, J.C.; Dykes, J.K.; Luquez, C.L.; Maslanka, S.E.; Barr, J.R. Detection of Botulinum Toxins A, B, E, and F in Foods by Endopep-MS. J Agric Food Chem 2015, 63, 1133-1141, https://doi.org/10.1021/jf505482b.

28. Nakhjavan, B.; Ahmed, N.S.; Khosravifard, M. Development of an Improved Method of Sample Extraction and Quantitation of Multi-Mycotoxin in Feed by LC-MS/MS. Toxins 2020, 12, https://dx.doi.org/10.3390\%2Ftoxins12070462.

29. Panasiuk, L.; Jedziniak, P.; Pietruszka, K.; Posyniak, A. Simultaneous determination of deoxynivalenol, its modified forms, nivalenol and fusarenone-X in feedstuffs by the liquid chromatography-tandem mass spectrometry method. Toxins 2020, 12, https://doi.org/10.3390/toxins12060362.

30. Sharma, S.K.; Ferreira, J.L.; Eblen, B.S.; Whiting, R.C. Detection of type A, B, E, and F Clostridium botulinum neurotoxins in foods by using an amplified Enzyme-Linked Immunosorbent Assay with digoxigenin-labeled antibodies. Appl Environ Microbiol 2006, 72, 1231-1238, https://doi.org/10.1128/AEM.72.2.1231-1238.2006.

31. Girigoswami, K.; Girigoswami, A. A Review on Role of Nanosensors in Detecting Cellular miRNA Expression in Colorectal Cancer. Endocr Metab Immune Disord Drug Targets 2021, 21, 12-26, https://doi.org/10.2174/1871530320666200515115723.

32. Thendral, V.; Dharshni, T.; Ramalakshmi, M.; Girigoswami, A.; Girigoswami, K. Cerium oxide nanocluster based nanobiosensor for ROS detection. Biocatal Agric Biotech 2019, 19, https://doi.org/10.1016/j.bcab.2019.101124.

33. Metkar, S.K.; Girigoswami, K. Diagnostic biosensors in medicine- a review. Biocatal Agric Biotech 2019, 17, 271-283, https://doi.org/10.1016/j.bcab.2018.11.029.

34. Girigoswami, K.; Akhtar, N. Nanobiosensors and fluorescence based biosensors: An overview. Int J Nano Dimens 2019, 10, 1-17.

35. Sharma, A.; Goud, K.Y.; Hayat, A.; Bhand, S.; Marty, J.L. Recent advances in electrochemical-based sensing platforms for aflatoxins detection. Chemosensors 2017, 5, https://doi.org/10.3390/chemosensors5010001.

36. Vikrant, K.; Bhardwaj, N.; Bhardwaj, S.K.; Kim, K.-H.; Deep, A. Nanomaterials as efficient platforms for sensing DNA. Biomaterials 2019, 214, https://doi.org/10.1016/j.biomaterials.2019.05.026.

37. Vikrant, K.; Tsang, D.C.; Raza, N.; Giri, B.S.; Kukkar, D.; Kim, K.-H. Potential utility of metal-organic framework-based platform for sensing pesticides. ACS Appl Mater Interfaces 2018, 10, 8797-8817, https://doi.org/10.1021/acsami.8b00664.

38. Finklea, H.O.; Snider, D.A.; Fedyk, J.; Sabatani, E.; Gafni, Y.; Rubinstein, I. Characterization of octadecanethiol-coated gold electrodes as microarray electrodes by cyclic voltammetry and ac impedance spectroscopy. Langmuir 1993, 9, 3660-3667, https://doi.org/10.1021/la00036a050. 
39. Feng, X.; Huang, H.; Ye, Q.; Zhu, J.-J.; Hou, W. Ag/polypyrrole core- shell nanostructures: interface polymerization, characterization, and modification by gold nanoparticles. J Phys Chem C 2007, 111, 84638468, https://doi.org/10.1021/jp071140z.

40. Abdulbari, H.A.; Basheer, E.A. Electrochemical biosensors: electrode development, materials, design, and fabrication. Chem Bio Eng Rev 2017, 4, 92-105, https://doi.org/10.1002/cben.201600009.

41. Jeyapragasam, T.; Saraswathi, R. Electrochemical biosensing of carbofuran based on acetylcholinesterase immobilized onto iron oxide-chitosan nanocomposite. Sens Actuators B Chem 2014, 191, 681-687, https://doi.org/10.1016/j.snb.2013.10.054.

42. Pisoschi, A.M. Potentiometric biosensors: concept and analytical applications-an editorial. Biochem Anal Biochem 2016, 5, 19-20, https://doi.org/10.4172/2161-1009.1000e164.

43. Jia, W.-Z.; Wang, K.; Xia, X.-H. Elimination of electrochemical interferences in glucose biosensors. $\operatorname{Tr} A C$ Trends Anal Chem 2010, 29, 306-318, https://doi.org/10.1016/j.trac.2010.01.006.

44. Gupta, R.; Raza, N.; Bhardwaj, S.K.; Vikrant, K.; Kim, K.H.; Bhardwaj, N. Advances in nanomaterial-based electrochemical biosensors for the detection of microbial toxins, pathogenic bacteria in food matrices. $J$ Hazard Mater 2021, 401, https://doi.org/10.1016/j.jhazmat.2020.123379.

45. Ramachandran, R.; Chen, T.-W.; Chen, S.-M.; Baskar, T.; Kannan, R.; Elumalai, P.; Raja, P.; Jeyapragasam, T.; Dinakaran, K. A review of the advanced developments of electrochemical sensors for the detection of toxic and bioactive molecules. Inorg Chem Frontiers 2019, 6, 3418-3439, https://doi.org/10.1039/C9QI00602H.

46. Azzouz, A.; Goud, K.Y.; Raza, N.; Ballesteros, E.; Lee, S.-E.; Hong, J.; Deep, A.; Kim, K.-H. Nanomaterialbased electrochemical sensors for the detection of neurochemicals in biological matrices. Trends Anal Chem 2019, 110, 15-34, https://doi.org/10.1016/j.trac.2018.08.002.

47. Evtugyn, G.; Hianik, T. Electrochemical immuno-and aptasensors for mycotoxin determination. Chemosensors 2019, 7, https://doi.org/10.3390/chemosensors7010010.

48. Shereema, R.M.; Rao, T.P.; Sameer Kumar, V.B.; Sruthi, T.V.; Vishnu, R.; Prabhu, G.R.D.; Sharath Shankar, S. Individual and simultaneous electrochemical determination of metanil yellow and curcumin on carbon quantum dots based glassy carbon electrode. Mater Sci Eng C Mater Biol Appl 2018, 93, 21-27, https://doi.org/10.1016/j.msec.2018.07.055.

49. Shah, A. A Novel Electrochemical Nanosensor for the Simultaneous Sensing of Two Toxic Food Dyes. ACS Omega 2020, 5, 6187-6193, https://doi.org/10.1021/acsomega.0c00354.

50. Mahato, K.; Kumar, S.; Srivastava, A.; Maurya, P.K.; Singh, R.; Chandra, P. Electrochemical immunosensors: fundamentals and applications in clinical diagnostics. In: Handbook of Immunoassay Technologies. Eds. Vashist, S.K., Luong, J.H.T. Academic Press, 2018; pp. 359-414, https://doi.org/10.1016/B978-0-12-811762-0.00014-1.

51. He, Y.; Wen, C.-Y.; Guo, Z.-J.; Huang, Y.-F. Noble metal nanomaterial-based aptasensors for microbial toxin detection. J Food Drug Anal 2020, 28, 508-520, https://doi.org/10.38212/2224-6614.1155.

52. Lv, M.; Liu, Y.; Geng, J.; Kou, X.; Xin, Z.; Yang, D. Engineering nanomaterials-based biosensors for food safety detection. Biosen Bioelectron 2018, 106, 122-128, https://doi.org/10.1016/j.bios.2018.01.049.

53. Malhotra, B.D.; Srivastava, S.; Ali, M.A.; Singh, C. Nanomaterial-Based Biosensors for Food Toxin Detection. Appl Biochem Biotechnol 2014, 174, 880-896, https://doi.org/10.1007/s12010-014-0993-0.

54. Malhotra, B.; Srivastava, S.; Augustine, S. Biosensors for food toxin detection: carbon nanotubes and graphene. MRS Proceedings 2015, 1725, 24-34, https://doi.org/10.1557/opl.2015.165.

55. Rovina, K.; Shaeera, S.N.; Vonnie, J.M.; Yi, S.X. Recent biosensors technologies for detection of mycotoxin in food products. Intech open 2019, https://doi.org/10.5772/intechopen.89022.

56. Nikoleli, G.P.; Nikolelis, D.P.; Siontorou, C.G.; Karapetis, S.; Varzakas, T. Novel Biosensors for the Rapid Detection of Toxicants in Foods. Adv Food Nutr Res 2018, 84, 57-102, https://doi.org/10.1016/bs.afnr.2018.01.003.

57. Olaoye, O.O.; Manderville, R.A. Aptamer Utility in Sensor Platforms for the Detection of Toxins and Heavy Metals. J Toxins 2017, 4, https://doi.org/10.13188/2328-1723.1000016.

58. Pietschmann, J.; Spiegel, H.; Krause, H.-J.; Schillberg, S.; Schröper, F. Sensitive Aflatoxin B1 Detection Using Nanoparticle-Based Competitive Magnetic Immunodetection. Toxins 2020, 12, https://doi.org/10.3390/toxins12050337.

59. Qian, M.; Hu, W.; Wang, L.; Wang, Y.; Dong, Y. A Non-Enzyme and Non-Label Sensitive Fluorescent Aptasensor Based on Simulation-Assisted and Target-Triggered Hairpin Probe Self-Assembly for Ochratoxin a Detection. Toxins 2020, 12, https://doi.org/10.3390/toxins12060376.

60. Sui, Z.; Wu, W.; Komiyama, M.; Liang, X. Highly Sensitive and Selective Detection of Food Toxin Using Three Functional DNA Hairpins. Chem Lett 2018, 47, 1026-1028, https://doi.org/10.1246/cl.180357.

61. Azad, T.; Ahmed, S. Common milk adulteration and their detection techniques. Int J Food Contamination 2016, 3, https://doi.org/10.1186/s40550-016-0045-3.

62. Var, I.; Kabak, B. Detection of aflatoxin M1 in milk and dairy products consumed in Adana, Turkey. Int $J$ Dairy Tech 2009, 62, 15-18, https://doi.org/10.1111/j.1471-0307.2008.00440.x. 
63. Hao, X.J.; Zhou, X.H.; Zhang, Y.; Liu, L.H.; Long, F.; Song, L.; Shi, H.C. Melamine detection in dairy products by using a reusable evanescent wave fiber-optic biosensor. Sens Actuators B Chem 2014, 204, 682687, https://doi.org/10.1016/j.snb.2014.08.023.

64. Konieczna, A.; Rutkowska, A.; Rachoń, D. Health risk of exposure to Bisphenol A (BPA). Rocz Panstw Zakl Hig 2015, 66, 5-11.

65. Reis, A.L.; Montanhini, M.; Bittencourt, J.V.; Destro, M.T.; Bersot, L.S. Gene detection and toxin production evaluation of hemolysin BL of Bacillus cereus isolated from milk and dairy products marketed in Brazil. Brazilian J Microbiol 2013, 44, 1195-1198, https://doi.org/10.1590/s1517-83822013000400024.

66. Mustafa, F.; Andreescu, S. Nanotechnology-based approaches for food sensing and packaging applications. RSC Adv 2020, 10, https://doi.org/10.1039/D0RA01084G.

67. Radoi, A.; Targa, M.; Prieto-Simon, B.; Marty, J.L. Enzyme-Linked Immunosorbent Assay (ELISA) based on superparamagnetic nanoparticles for aflatoxin M1 detection. Talanta 2008, 77, 138-143, https://doi.org/10.1016/j.talanta.2008.05.048.

68. Zhang, Z.; Lin, M.; Zhang, S.;Vardhanabhuti, B. Detection of aflatoxin M1 in milk by dynamic light scattering coupled with superparamagnetic beads and gold nanoprobes. J Agric Food Chem 2013, 61, 45204525, https://doi.org/10.1021/jf400043z.

69. Xue, Z.; Zhang, Y.; Yu, W.; Zhang, J.; Wang, J.; Wan, F.; Kim, Y.; Liu, Y.; Kou, X. Recent advances in aflatoxin B1 detection based on nanotechnology and nanomaterials-A review. Anal Chim Acta 2019, 1069, 1-27, https://doi.org/10.1016/j.aca.2019.04.032.

70. Wei, F.; Lam, R.; Cheng, S.; Lu, S.; Ho, D.; Li, N. Rapid detection of melamine in whole milk mediated by unmodified gold nanoparticles. Appl Phys Lett 2010, 96, https://dx.doi.org/10.1063\%2F1.3373325.

71. Su, H.; Fan, H.; Ai, S.; Wu, N.; Fan, H.; Bian, P.; Liu, J. Selective determination of melamine in milk samples using 3-mercapto-1-propanesulfonate-modified gold nanoparticles as colorimetric probe. Talanta 2011, 85, 1338-1343, https://doi.org/10.1016/j.talanta.2011.06.017.

72. Yin, H.; Cui, L.; Chen, Q.; Shi, W.; Ai, S.; Zhu, L.; Lu, L. Amperometric determination of bisphenol A in milk using PAMAM-Fe3O4 modified glassy carbon electrode. Food Chem 2011, 125, 1097-1103, https://doi.org/10.1016/j.foodchem.2010.09.098.

73. Yang, L.; Chen, Y.; Shen, Y.; Yang, M.; Li, X.; Han, X.; Jiang, X.; Zhao, B. SERS strategy based on the modified Au nanoparticles for highly sensitive detection of bisphenol A residues in milk. Talanta 2018, 179, 37-42, https://doi.org/10.1016/j.talanta.2017.10.055.

74. Bruno, J.G.; Carrillo, M.P. Development of aptamer beacons for rapid presumptive detection of Bacillus spores. J. Fluoresc 2012, 22, 915-924, https://doi.org/10.1007/s10895-011-1030-0.

75. Mazzaracchio, V.; Neagu, D.; Porchetta, A.; Marcoccio, E.; Pomponi, A.; Faggioni, G.; D’Amore, N.; Notargiacomo, A.; Pea, M.; Moscone, D. A label-free impedimetric aptasensor for the detection of Bacillus anthracis spore simulant. Biosens Bioelectron 2019, 126, 640-646, https://doi.org/10.1016/j.bios.2018.11.017.

76. Kong, M.; Sim, J.; Kang, T.; Nguyen, H.H.; Park, H.K.; Chung, B.H.; Ryu, S. A novel and highly specific phage endolysin cell wall binding domain for detection of Bacillus cereus. Eur Biophys J 2015, 44, 437-446, https://doi.org/10.1007/s00249-015-1044-7.

77. Vidic, J.; Chaix, C.; Manzano, M.; Heyndrickx, M. Food Sensing: Detection of Bacillus cereus Spores in Dairy Products. Biosensors (Basel) 2020, 10, https://doi.org/10.3390/bios10030015. 